COMMENT. Lack of familiarity with guidelines for the management of concussion in sports-related head injuries was one explanation for the frequency of inappropriate discharge instructions. The Colorado

Medical Society guidelines are summarized as follows:

- Grade 1. Confusion without amnesia or loss of consciousness. Return to sport permitted after 20 minutes, if no symptoms at rest or on exertion.

- Grade 2. Confusion with amnesia but no loss of consciousness. Observe 24 hours. Return permitted after 1 week without symptoms.

- Grade 3. Any loss of consciousness. Admit if neuro exam abnormal. Return permitted after 1 month, if asymptomatic for past 2 weeks. Football accounted for $55 \%$, baseball $12 \%$, soccer $6 \%$, and wrestling $3 \%$ of injuries in the above study. Documentation of discharge instructions is important for medico-legal reasons.

\title{
PERPETRATORS OF ABUSIVE HEAD TRAUMA
}

The identity of abusers and their relationship to victims was studied by reviewing medical charts of 151 head injured children, aged 24 months or younger, seen at the Children's Hospital, Denver, CO from Jan 1982 - Jan 1994. All infants had documented intracranial bleeding and other injuries. Male infants were abused more frequently than female (60\% v 40\%); and $23 \%$ died. Male perpetrators outnumbered females 2.2:1. Fathers and boyfriends were the most common perpetrators: $37 \%$ and 20\%, respectively. From 1989 to 1993, the percentage of infants abused by men nearly doubled. Female baby-sitters were a large, previously unrecognized group of perpetrators, accounting for $17 \%$. Mothers were responsible for only 12\%. (Starling SP et al. Abusive head trauma: The relationship of perpetrators to their victims. Pediatrics February 1995;95:259-262). (Reprints: Dr SP Starling, The Children's Hospital, B-138, 1056 East 19 th Ave, Denver, CO 80218).

COMMENT. These findings should focus attention on baby-sitters as a previously unrecognized group of abusers. Despite an increase in support services and media publicity, non-accidental head injury ("shaken baby syndrome") remains the leading cause of death or longterm disability among child abuse cases. Subtle or mild trauma is particularly difficult to diagnose, often mistaken for viral illness, feeding problems, or infant colic. Shaking injuries are rare after the second year. The most common age for whiplash abuse is 5 months, when the head is large in relation to the body, and the neck muscles and head control are weak. (Brown JK, Minns RA, 1993). See Progress in Pediatric Neurology II, Chicago, PNB Publ, 1994. pp387-396, for an overview of head injury in children by Dr J Keith Brown, Edinburgh, and various recent articles and editorial commentaries.

\section{LEARNING AND BEHAVIOR DISORDERS}

\section{MECHANISM OF SUGAR-INDUCED BEHAVIORAL EFFECTS}

The adrenomedullary response to a standard oral glucose load $(1.75$ $\mathrm{gm} / \mathrm{kg}$; maximum, $120 \mathrm{gm}$ ) and susceptibility to neuroglycopenia (assessed by the hypoglycemic clamp and measurements of P300 auditory evoked potentials [AEP]) were studied in 25 healthy children ( 8 - 16 years of age) compared to 23 young adults at the Children's Clinical Research Center, Yale University School 